\title{
The Significance of Contexts in Positive Youth Development Foreword
}

\author{
Ana Kozina' and Nora Wiium² \\ 'Educational Research Institute, Ljubljana, Slovenia \\ ${ }^{2}$ University of Bergen, Norway
}

Positive Youth Development (PYD; Lerner et al., 2021) has gained the attention of researchers and practitioners not only in the USA, from where the perspective originated, but in recent decades across Europe as well. PYD, based on relational developmental systems theory, focuses on young people's strengths and the importance of the contexts in which they interact. The relational developmental systems theory states that all aspects of human development are a function of the two-way interaction between the individual and their contexts (e.g., school, family, community, society; Overton, 2015). Accordingly, young people hold potencials that can support their optimal development when provided with suitable environmental opportunities (Porter, 2010). The principal assumption is that young people will develop positively when their strengths (internal assets) are aligned with the resources in their contexts (external assets). This alignment, if optimal, can lead to adaptive developmental regulations whereby thriving or positive youth outcomes (i.e., the ${ }_{5}$ Cs: competence, confidence, character, caring, connectedness) become more probable, and risky or problem behaviours (e.g., early school leaving, aggression, anxiety) less frequent. Moreover, youth who are thriving will engage in prosocial behaviours and contribute to their own development and the development of others in their contexts. The support mechanisms for positive development (internal assets, external assets) may vary across individuals and subgroups (e.g., youth with a migrant status, youth in transition, youth from different language backgrounds). This monograph investigates the mechanisms 
that support young people's positive development across different contexts and subgroups, considering both international and Slovenian perspectives.

The book is divided into two sections: PYD in international contexts and PYD across contexts in Slovenia. The first section (PYD in international contexts) focuses on the interplay of developmental assets, the ${ }_{5} \mathrm{Cs}$, and youth outcomes (e.g., thriving indicators, risky behaviours). The first of the three chapters in this section written by Nag Delgado, Huang, and Wiium (Positive Youth Development and Thriving in Norwegian Youth) investigates and endorses the importance of both internal and external developmental assets for Norwegian youth to thrive. Written by Uka, Musliu, Mehmeti, Bajgora, and Isufi, the second chapter (The effects of the ${ }_{5} \mathrm{Cs}$ and Developmental Assets on Well-being and Satisfaction with Life among Youth in Kosovo) explores and reports associations between the developmental assets and the ${ }_{5} \mathrm{Cs}$ as well as well-being and life satisfaction in Kosovo. The section concludes with a contribution by Gomez-Baya, Martín-Gómez, Branquinho, Tomé and Gaspar de Matos (Developmental Assets and Healthy Lifestyles among Spanish Youth) that considers and confirms the role played by developmental assets in risky behaviours and healthy lifestyle among Spanish youth. Together, these three chapters contribute empirical evidence regarding the importance of developmental assets and the ${ }_{5} \mathrm{Cs}$ in three European contexts. A review of PYD frameworks in the American context postulates that the ${ }_{5} \mathrm{Cs}$ model of PYD is the most empirically supported framework to date (Heck \& Subramaniam, 2009). However, concerns about the ${ }_{5}$ Cs model's generalisability outside of the USA created a need to explore the PYD perspective in non-US contexts, as often described in the scientific literature (e.g., Koller \& Verma, 2017). These three chapters add to the generalisability of the PYD perspective since they are based on three European contexts. Further, these contributions add theoretical and practical value to the PYD perspective with comparable findings able to inform prevention and intervention programmes across countries and for a range of young people.

The second section on PYD across contexts in Slovenia concentrates on specific Slovenian contexts that may play an important role in positive youth development. The six chapters in this section cover two important contexts: the school context and the context of migration and language.

For the school context, Pivec's chapter (Measuring Positive Youth Development in Slovenia with a Focus on Gender and School-Level Differences) introduces the Slovenian context by analysing gender and 
school-level differences in positive development after first presenting the PYD measures' psychometric properties in Slovenia. Reliable and valid measures of PYD are the first step in drawing valid conclusions and, in this respect, the article thus provides solid grounds for future research on PYD in Slovenia. The section continues with another chapter on the school context (Preventing bullying: Peer Culture as the Crucial Developmental Context in Adolescence), where the author Košir presents peer culture as a significant context while studying bullying and victimisation in the school setting. Further, Gradišek's article (Character Strengths of First-year Student Teachers and the Five Cs of the Positive Youth Development Framework: A Mixed-methods Study) considers young people's experiences during their transition to higher education in an innovative interplay of the PYD perspective and positive psychology. Earlier research (e.g., Eccles et al., 1993; Wentzel, 2009) suggests that youth during the transition period from one educational level to another are likely to find it difficult to establish new relationships and develop social support. Youth in educational transition face several challenges, such as integrating into a new school and engaging with new classmates. Gradišek's chapter presents several support mechanisms in the form of selected character strengths that may contribute to such young people's positive development.

The section on PYD across Contexts in Slovenia continues with three chapters on migration and language contexts. Migration status as a risk factor is linked with negative youth outcomes like difficulties at school (Strohmeier \& Schmitt-Rodermund, 2008), communicative anxiety and lower linguistic competence (Sevinç \& Dewaele, 2016; Sevinç \& Backus, 2017) across various contexts. In this regard, Mlekuž's chapter (Components of Positive Youth Development among Native Students and Students with an Immigrant Background in the Slovenian Educational Environment) explores differences in the positive adaptation of immigrant youth versus non-immigrant youth in Slovenia, and highlights several areas of concern associated with greater difficulties for immigrant youth. To address some of these concerns, Lampret's review (Contact-based Interventions to Reduce Ethnic Prejudice against Migrants and Ethnic Minorities in the School Context: A Systematic Literature Review) of the existing literature on effective interventions for reducing ethnic prejudice against migrants, refugees and ethnic minorities in schools sets out the practical implications of implementing a successful intervention in schools. Finally, Žmavc's article (Mobilising the potential held by one's entire linguistic repertoire for positive youth 
development) combines theoretical perspectives on positive youth development and multilinguism to study how language as a context, especially languages that are primarily used, can impact youth development. The monograph concludes with two commentaries that discuss the significance of the national and international research presented in the nine chapters

Overall, this monograph offers a starting point for PYD research in Slovenia with clear links to the research in international settings. An overview is also provided of the complexities of the various contexts of Europe and Slovenia able to influence positive youth development. Thus, while the research reported in the monograph focuses on the Slovenian context, it is ambitious enough to also reach beyond the country's borders to include the international research community. In addition to novelty and innovation in a scientific context, the presented research is socially relevant, especially for its inclusion of immigrants and other young people at risk in the school and wider social contexts.

\section{Acknowledgements}

The monograph is a part of The Cross-National Project on Positive Youth Development (CN-PYD) and was partly supported by The Slovenian Research Agency as part of the project Positive Youth Development in Slovenia: Developmental Pathways in the Context of Migration (PYD-SI Model) [J5-1781].

\section{References}

Eccles, J. S., Midgley, C., Wigfield, A., Buchanan, C. M., Reuman, D., Flanagan, C., \& Mac Iver, D. (1993). Development during adolescence: The impact of stage-environment fit on young adolescents' experiences in schools and in families. American Psychologist, 48, 90-101. https://doi. org/10.1037/0003-066X.48.2.90

Heck, K. E., \& Subramaniam, A. (2009). Youth development Frameworks. [Monograph]. 4-H Center for Youth Development, University of California.

Koller, S. H., \& Verma, S. (2017). Commentary on cross-cultural perspectives on positive youth development with implications for intervention research. Child Development, 88, 1178-1182. https://doi.org/10.1111/cdev.12873

Lerner, R. M., Jervis, P., \& Bornstein, M. H. (2021). Enhancing the international study of positive youth development: Process, specificity, and the 
sample case of character virtues. Journal of Youth Development, 16(2-3), 402-422. https://doi.org/10.5195/jyd.2021.1042

Overton, W. F. (2015). Processes, relations, and relational-developmental-systems. In R. M. Lerner, Handbook of Child Psychology and Developmental Science, (pp. 1-54). Hoboken, Wiley. https://doi.org/10.1002/9781118963418. childpsy102

Porter, R. I. (2010). Invited commentary: The Positive Youth Development perspective is an

exciting direction for adolescent and family policies and programs. Journal of Youth and Adolescence, 39, 839-842. https://doi.org/10.1007/ s10964-010-9554-1

Sevinç, Y. \& Backus, A. (2017). Anxiety, language use and linguistic competence in an immigrant context: a vicious circle? International Journal of Bilingual Education and Bilingualism, 1-19. https://doi.org/10.1080/136700 50.2017 .1306021

Sevinç, Y. \& Dewaele, J. M. (2016). Heritage language anxiety and majority language anxiety among Turkish immigrants in the Netherlands. International Journal of Bilingualism, 22(2), 159-179. https:/doi. org/10.1177/0123456789123456

Strohmeier, D., \& Schmitt-Rodermund, E. (2008). Immigrant youth in European countries: The manifold challenges of adaptation. European Journal of Developmental Psychology, 5(2), 129-137. https://doi. org/10.1080/17405620701556953

Wentzel, K. R., Barry, C. M., \& Caldwell, K. A. (2004). Friendships in middle school: influences on motivation and school adjustment. Journal of Educational Psychology, 96, 195-203. https://oi. org/10.1037/0022-0663.96.2.195 